\title{
Pseudotumoral Patella Injury. About a Case
}

\section{José Enrique Pérez González ${ }^{1 *}$, Alicia Tamayo Figueroa ${ }^{2}$, Carlos González de Varona ${ }^{3}$, Ragnar Calzado Calderón ${ }^{2}$, Vilma Rondón García $^{4}$ and Juan Carlos Alvarez Rodríguez ${ }^{5}$}

${ }^{1}$ Specialist in Orthopedics and Traumatology, International Orthopedic Scientific Complex "Frank Pais", La Lisa, Havana, Cuba

${ }^{2}$ Specialist 2nd Degree in Orthopedics and Traumatology, International Orthopedic Scientific Complex "Frank Pais", La Lisa, Havana, Cuba

${ }^{3}$ Specialist 1st Degree in Comprehensive Medicine and Orthopedics and Traumatology, Assistant Professor, International Orthopedic Scientific Complex "Frank Pais", La Lisa, Havana, Cuba

${ }^{4}$ Specialist 2nd Degree in Radiology, International Orthopedic Scientific Complex

"Frank Pais", La Lisa, Havana, Cuba

5Bachelor's Degree in Defectology, Physiotherapist, Assistant Professor, International Orthopedic Scientific Complex "Frank Pais", La Lisa, Havana, Cuba

*Corresponding Author: José Enrique Pérez González, Specialist in Orthopedics and Traumatology, International Orthopedic Scientific Complex "Frank Pais", La Lisa, Havana, Cuba.
Received: March 09, 2021

Published: November 23, 2021

(C) All rights are reserved by José Enrique

Pérez González., et al.

\section{Abstract}

Aneurysmal Bone Cyst (ABC) is a pseudotumoral lesion that is predominantly seen during childhood, and 76\% of cases occur in patients under 20 years of age and with a slight predominance of the female sex. Below is a case of a 50-year-old male patient who when performing the scan shows inflammation of the right knee that was progressively increasing accompanied by pain and limitation for extension. Blood and chemistry test, X-rays, CT scans are performed. Sample is taken for biopsy with diagnosis Aneurysmal Bone Cyst ( $\mathrm{ABC}$ ) of the patella, taken to the salon, given full patellectomy and physiotherapy begins at $24 \mathrm{~h}$ of surgery.

Keywords: Cyst-Aneurysmal; Pseudotumoral Injury; Osteolytic Injury

\section{Introduction}

The term Aneurismal Bone Cyst (ABC) was first used by Jaffe and Liechtenstein to describe two samples of blood-filled cysts in which the tissue on their wall contained large spaces, areas of hemosiderin deposits, giant cells and some bone trabeculated. In a later publication, Jaffe chose the aneurysmal bone cyst designation as a descriptive term for this injury in order to emphasize its in suffering [1-3] appearance. As a concept it is an expansive osteolytic lesion consisting of spaces of variable size filled with blood and separated from each other by partitions of connective tissue, in which bone tissue or osteoid trabeculated can be seen, as well as giant osteoclastic cells.

These cysts usually occur in patients under the age of 30 with predominance in childhood, $76 \%$ appear before age 20 , with greater representativeness in the female sex, the most common seat of the tumor is in the metaphysis of the long bones, their situation is usually eccentric and appears attached to the bulging of the perios- 
teum, although it can also appear in the diaphysis, flat bones, short tubular bones and even the spine. Although the cause of the injury is unknown, local hemodynamic alterations related to venous obstruction or the presence of arteriovenous fistulas [1-8] appearance to play an important role.

Clinically it is characterized by pain, increased volume and limited joint mobility. Spinal locations occur with pain of the affected segment, mobility limitation and root or spinal disorders, first irritation and after compression that can reach paraplegia [9-11].

The radiological aspect of $\mathrm{ABC}$ varies according to the location of the lesion:

- In the long bones: It has a multiloculated cystic cavity that takes on the appearance of a "bee, bread or soap bubbles". The boundaries of the cyst have smooth walls, with very precise edges with pericystic sclerosis. The aneurysm expansions are covered by a thin layer of periosteal bone, in eggshell, which at its limits can take on the appearance of a Codman triangle.

- In the vertebrae: This cyst has a predilection for the lumbar spine. It also produces a lithic image that can affect multiple vertebrae. It is usually located in the posterior elements of the vertebra, sheets and spiny apophysis, which erodes reaching the pedicle that can also be affected. The location is almost always eccentric and extends to the neighboring soft parts. In addition, it can be observed as the rejected periosteal delimits the periphery of the tumor $[3,5,12,13]$.

Tests such as axial tomography or magnetic resonance are necessary studies and better show the anatomy of the lesion, its extension within the bone and the commitment of soft parts $[1,5,14]$.

Microscopically: The histological image corresponds to that of different blood lakes bordered by a fibrous membrane, without endothelium. Conjunctive tissue partitions show areas of ontogenesis, is richly vascularized with blood vessels ranging from small to large caliber and in other areas abundant giant cells $[3,16]$.

Corticosteroid injection may be used. In large lesions and vertebral locations, a single or repeated selective arterial embolization is advised.

You should always remember the benign nature of the injury and practice conservative surgery accordingly. When the size and/ or location of the cyst permit it should be used to cure the cystic bed, followed by grafting. Block resection is indicated in bones such as fibula. At the vertebral level, surgery should be performed whenever possible in order to empty the lesion and fixing the affected segment in a stable manner. Only surgically inaccessible lesions use radiation therapy, always aware of the risk of osteogenic sarcoma post radiation [1,9-11,15-17].

\section{Clinical Case}

We present a case of a 50-year-old male adult with a history of health, oar trainer, who comes to our service because he started with inflammation of the right knee that was progressively increasing accompanied by pain and limitation for the extension of that knee. He took several nonsteroidal anti-inflammatory treatments and physiotherapy worsening his symptomatology.

You have a simple radiological study of the knee in two views where osteolytic lesion is observed at the patella level so admission is decided for study and treatment.

\section{Physical examination}

Normolinean male patient with claudicate gait at the expense of the lower right limb and with the help of crutches.

\section{Inspection}

Right knee: Synovitis without changes of local coloration, you can see smooth and bright volume increase on the patella. No collateral circulation.

Palpation: The above is checked by feeling induration of the anterior face of the knee that is painful, crackling and has increased local temperature. Soft, mobile and non-painful inguinal adenopathy are palpable.

Joint mobility:

- Knee flexion: 85 grades.

- Knee extension: 85 to 20 grades.

- $\quad$ Special maneuvers: Impossible to perform by pain.

- Measuring: No discrepancy of lower limbs.

- Tone and trophism: Decreased at the level of the right quadriceps.

- Reflections and sensitivity: Preserved. 
Lab test

- $\quad$ WBC: $6.8 \times 10^{9} / \mathrm{L}$.

- $\quad \mathrm{Hb}: 14.5 \mathrm{~g} / \mathrm{dl}$.

- Erythrocyte sedimentation rate (ESR): $15 \mathrm{~mm} / \mathrm{h}$.

- $\quad$ Platelets count: $209000 / \mu \mathrm{L}$.

- Glucose: $5.2 \mathrm{mmol} / \mathrm{L}$.

- $\quad$ Ca: $2.1 \mathrm{mEq} / \mathrm{L}$.

- $\quad$ Phosphate: $1.2 \mathrm{mg} / \mathrm{dl}$.

- $\quad$ Serum glutamic-piruvic transaminase (SGPT) 29 U/l.

- Glutamic oxaloacetic transaminase (GOT) $34 \mathrm{U} / \mathrm{l}$.

- $\quad$ Alkaline phosphatase: 147 UI/l.

- $\quad$ Creatinine: $80 \mathrm{mg} / \mathrm{dl}$.

- $\quad$ Uric acid: $345 \mathrm{mg} / \mathrm{dl}$.

Anteroposterior x-ray: shows an increase in the diameter of the patella with thinning of the corticals associated with osteolytic imaging that encompasses the entire bone with bone trabecular, without periosteal reaction (Figure 1).
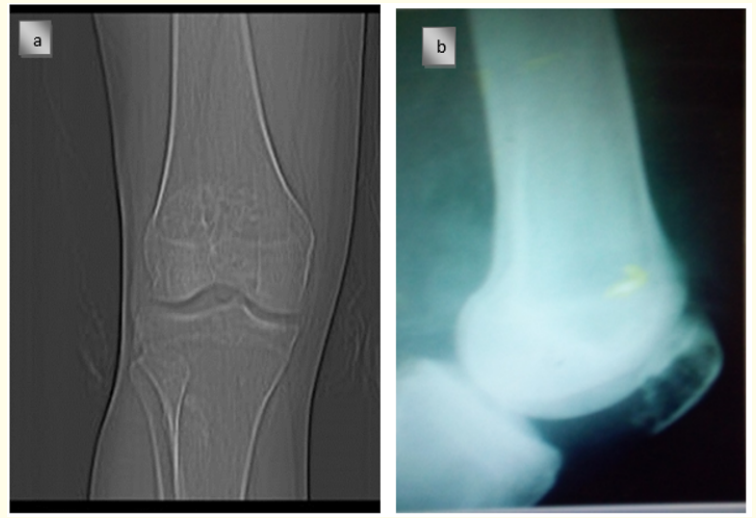

Figure 1: 1a AP and 1b lateral, X-ray of the right knee.

CT scan- shows osteolytic lesion with liquid content inside cystic cavities and cortical redness (Figure 2).

Macroscopically the lesion corresponds to what is described by pathological anatomy (Figure 3).

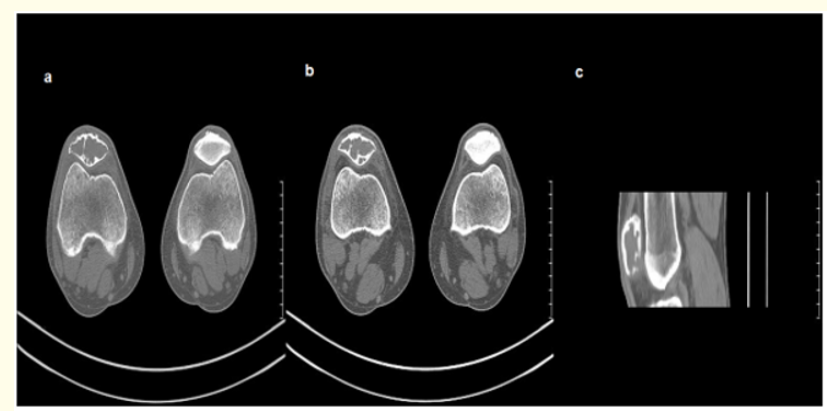

Figure 2: Axial tomography view (a, b) and sagittal (c) of the patella.
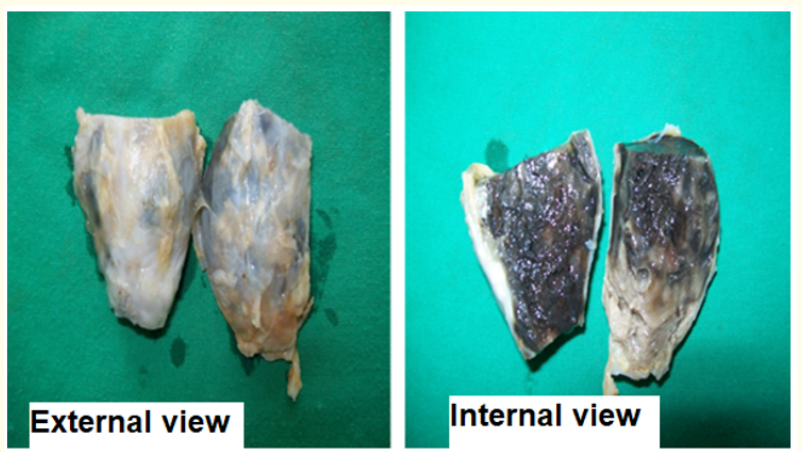

Figure 3

Treatment

It is performed in the first time in the incisional biopsy operating room, giving as a symptomatic bone cyst.

Subsequently surgical treatment is applied by patellectomy total. It is immobilized with plaster fit for 21 days starting rehabilitation with isometric contractions of the member at $24 \mathrm{~h}$ of operation, once removal the immobilization is carried out electrical stimulation of the quadriceps, free and assisted active exercises to improve joint and muscle function and facilitate the early incorporation of the patient into the activities of daily life.

Pathological anatomy result:

- Aneurysmal patella bone cyst. 


\section{Discussion}

Aneurismal Bone Cyst (ABC)is most often observed during childhood, with predominance of age earlier than 20 years, prevailing the female sex discreetly over the male, its most frequent location is in the metaphysis of the long bones, in humerus and proximal tibia, being very rare its appearance in the patella with very few cases published in the literature. Histologically it can harbor focuses of other tumors (Giant cells tumor before, chondroblastoma, osteoblastoma, osteosarcoma, pleomorphic sarcoma, etc). It is treated by resection or curing, followed by grafting if the residual defect is large.

The behavior to follow in our case was the complete excision of the patella, (total patellectomy) by the age of the patient, as well as the radiological changes present determined by tuning and rupture of the cortical in his joint face, we consider It would not be functional to perform bone graft or PMMA (surgical cement) filling because the incorporation of either would cause interference in the joint mechanics which would not allow proper rehabilitation and recovery of knee function. After surgical treatment any radiotherapy was recommended.

\section{Conclusion}

Although ABCs are benign tumors, they sometimes evolve torpidly and relapsing masking other malignant tumor conditions that would worsen the prognosis. This case was followed by outpatient consultation of the Peripheral Tumors Service and physiotherapy, achieving a good functional resulted of the knee with satisfactory and high evolution at 5 years. We recommend strict monitoring of this type of injury considering that, although this is not a common location, such injury may appear on the patella.

\section{Conflict of Interest}

The authors of this work certify that there are no conflicts of interest in the realization of this work.

\section{Bibliography}

1. Salazar Villanea Roberto. "Bone cyst Aneurysmattic". Medical Journal of Costa Rica and Central America LXX 605 (2013): 175-180.

2. Velázquez Carranza N., et al. "Quiste oseoaneurismaticogiganteenhumero". Journal Andalusian Society of Traumatology (2020).
3. Jimenez-Avila JM., et al. "Quisteaneurysm lumbar spine. Medical-surgical experience. Report a case”. Mexican Orthopedic Act 25.2 (2011): 130-134.

4. Martínez Giménez JE., et al. "Cyst or aneurysm in children and adolescents”. Spanish Journal of Osteoarticular Surgery (2020).

5. Delgado Serrano PJ Abril Martin JC. "Aneurismatic bone cyst in sacrum". Pathology of the Locomotive Device (2020).as

6. Cuneo Alejandro M.D., et al. "QuisteAneurismatic Bone Pelviano Of Solid Variety. Report a case. Clinic of Traumatology and Pediatric Orthopedics. Faculty of Medicine". Pereira Rosell Hospital Center. Montevideo-Uruguay (2020).

7. Vergara Severiche Sindy., et al. "Aneurysm bone cyst. Filing a case". The Revista Colombiana de Entomología 29.2 (2018): 4924-4926.

8. Fraga García H., et al. "Polystotic aneurysm bone cyst". Revista Española de Cirugía Osteoaraticular (1991): 267-271.

9. Cowboy-Cervino E., et al. "Treatment of the aneurysm bone cyst of metacarpals with non-vascularized autologous fibula graft. Provision of two cases in children". Revista Iberoamericana de Cirugía 33.67 (2005): 56-61.

10. Soldado-Carrera F., et al. "Bone remodeling after surgical treatment of the aneurysm bone cyst of metacarpian location in the child". Revista Iberoamericana de Cirugía 30.64 (2004): 39-42.

11. S Doñate F and Gallach D. "Aneurismatic bone cyst in third metacarpal treated with non-vascularized fibula grafting. Ibero-American". Journal of Hand Surgery (2020).

12. Bueso Manuel. "Patela'satheticaneurysmorseo. Report a case". Revista Médica Hondureña 72 (2004): 139-141.

13. Orduñas Serra M., et al. "Treatment of benign bone tumors by liking and filling with methyl methacrylate". Revista Brasileira de Ortopedia 33.2 (1989): 179-184.

14. Lorfish Torres Hidalgo., et al. "A patient with cyst or aestheticaneurysm". Reviews in Clinical Medicine 13.1 (2020): 93-96.

15. Linares-González LM., et al. "Treatment and reconstruction in bone tumors of the humerus with unconventional PROsthetics type RIMAG". Mexican Orthopedic Act 28.1 (2014): 3-11.

16. Pacheco-Morán Julio Melo Santiago., et al. "Cyst or aneurysmatheticin the distal humerus. Report of a case and current treatment". Reverend Metro Science 26.1 (2018): 27-32. 
17. Fuentes P., et al. "Woman with tibiaí í tica". Valencian Health Agency (2020).

Volume 4 Issue 12 December 2021

(C) All rights are reserved by José Enrique Pérez

González., et al. 